NBER WORKING PAPER SERIES

\title{
ECONOMIC, NEUROBIOLOGICAL AND BEHAVIORAL PERSPECTIVES ON BUILDING AMERICA'S FUTURE WORKFORCE
}

\author{
Eric I. Knudsen \\ James J. Heckman \\ Judy L. Cameron \\ Jack P. Shonkoff \\ Working Paper 12298 \\ http://www.nber.org/papers/w12298

\begin{abstract}
NATIONAL BUREAU OF ECONOMIC RESEARCH
1050 Massachusetts Avenue

Cambridge, MA 02138
\end{abstract} \\ June 2006
}

The views expressed herein are those of the author(s) and do not necessarily reflect the views of the National Bureau of Economic Research.

(C)2006 by Eric I. Knudsen, James J. Heckman, Judy L. Cameron, and Jack P. Shonkoff. All rights reserved. Short sections of text, not to exceed two paragraphs, may be quoted without explicit permission provided that full credit, including (C) notice, is given to the source. 
Economic, Neurobiological and Behavioral Perspectives on Building America's Future Workforce

Eric I. Knudsen, James J. Heckman, Judy L. Cameron and Jack P. Shonkoff

NBER Working Paper No. 12298

June 2006

JEL No. J24

\begin{abstract}
A growing proportion of the U.S. workforce will have been raised in disadvantaged environments that are associated with relatively high proportions of individuals with diminished cognitive and social skills. A cross-disciplinary examination of research in economics, developmental psychology, and neurobiology reveals a striking convergence on a set of common principles that account for the potent effects of early environment on the capacity for human skill development. Central to these principles are the findings that early experiences have a uniquely powerful influence on the development of cognitive and social skills, as well as on brain architecture and neurochemistry; that both skill development and brain maturation are hierarchical processes in which higher level functions depend on, and build on, lower level functions; and that the capacity for change in the foundations of human skill development and neural circuitry is highest earlier in life and decreases over time. These findings lead to the conclusion that the most efficient strategy for strengthening the future workforce, both economically and neurobiologically, and for improving its quality of life is to invest in the environments of disadvantaged children during the early childhood years.
\end{abstract}

Eric I. Knudsen

Department of Neurobiology

Stanford University School of Medicine

Stanford, CA 94305-5125

aknudsen@stanford.edu

James J. Heckman

Department of Economics

University of Chicago

Chicago, IL 60637

and NBER

jjh@uchicago.edu
Judy L. Cameron

Department of Psychiatry

University of Pittsburgh

Pittsburgh, PA 15213

cameronj@ohsu.edu

Jack P. Shonkoff

The Heller School for Social Policy and

Management

Brandeis University

Waltham, MA 02454-9110

shonkoff@brandeis.edu 


\section{Economic, Neurobiological and Behavioral Perspectives on Building America's Future Workforce}

A growing proportion of the U.S. workforce will have been raised in disadvantaged environments that are associated with relatively high proportions of individuals with diminished cognitive and social skills. A cross-disciplinary examination of research in economics, developmental psychology, and neurobiology reveals a striking convergence on a set of common principles that account for the potent effects of early environment on the capacity for human skill development. Central to these principles are the findings that early experiences have a uniquely powerful influence on the development of cognitive and social skills, as well as on brain architecture and neurochemistry; that both skill development and brain maturation are hierarchical processes in which higher level functions depend on, and build on, lower level functions; and that the capacity for change in the foundations of human skill development and neural circuitry is highest earlier in life and decreases over time. These findings lead to the conclusion that the most efficient strategy for strengthening the future workforce, both economically and neurobiologically, and for improving its quality of life is to invest in the environments of disadvantaged children during the early childhood years.

The future success of the U.S. economy will depend in part on well-educated and highly resourceful workers who are capable of learning new skills so that they remain competitive in a continually changing global market. That success is in jeopardy because a growing fraction of the nation's workforce will consist of adults who were raised in disadvantaged environments, a segment of the population that has historically been less likely to attain high levels of education and skill development than the general population $(1,2)$.

Research in child development over the past several decades has led to an increasingly refined understanding of the characteristics of disadvantaged environments (3). Central to this concept is the statistical association between a select number of "risk factors" and the increased probability of adverse outcomes in the domains of cognitive, emotional and social development, leading to diminished economic success and decreased quality of life in adulthood. The most extensively studied risk factor is poverty, but others include limited parent education, parental 
mental health problems, significant social deprivation or neglect, and exposure to interpersonal violence (3-7).

Behavioral research confirms that the early years are foundational for a full range of human competencies and are a period of heightened sensitivity to the effects of both positive and negative experiences $(3,8)$. In a parallel fashion, studies of human capital formation indicate that the quality of the early childhood environment is a strong predictor of adult productivity (9), and that early enrichment for disadvantaged children increases the probability of later economic success (10). Although explanatory mechanisms for interpreting these correlations are still being developed, recent advances in neuroscience are illuminating, as they demonstrate the extent to which early experience influences the development of neural circuits that mediate cognitive, linguistic, emotional, and social capacities $(11,12)$.

This paper focuses on the striking convergence of four core concepts that have emerged from decades of mutually independent research in economics, neuroscience, and developmental psychology. First, the architecture of the brain and the process of skill formation are both influenced by an inextricable interaction between genetics and individual experience. Second, both the mastery of skills that are essential for economic success and the development of their underlying neural pathways follow hierarchical rules in a bottom-up sequence such that later attainments build on foundations that are laid down earlier. Third, cognitive, linguistic, social, and emotional competencies are interdependent, all are shaped powerfully by the experiences of the developing child, and all contribute to success in the workplace. Fourth, although adaptation continues throughout life, human abilities are formed in a predictable sequence of sensitive periods, during which the development of specific neural circuits and the behaviors they mediate are most plastic, and therefore optimally receptive to environmental influences.

\section{Early Experience Shapes the Foundation for Adult Productivity}

A landmark study commissioned by the Institute of Medicine and the National Research Council concluded that "virtually every aspect of early human development, from the brain's evolving circuitry to the child's capacity for empathy, is affected by the environments and experiences that are encountered in a cumulative fashion, beginning in the prenatal period and extending throughout the early childhood years." ((3), p.6). 
Independent econometric studies have reached similar conclusions. Extensive evidence indicates that cognitive, social, and emotional capacities play important roles in the attainment of adult economic productivity, and all are shaped by early life experiences. The most reliable data come from experiments that provided substantial enrichment of the early environments of children living in low-income families. Two of these investigations, the Perry Preschool Program and the Abecedarian Program (Box 1), are the most informative for the purposes of this discussion because they employed a random assignment design and collected long-term followup data (10). Both of these longitudinal studies demonstrated substantial, positive effects of early environmental enrichment on a range of cognitive (Fig. 1) and "non-cognitive" skills, school achievement, job performance, and social behaviors (Fig. 2), long after the intervention ended $(13,14)$. Data from non-controlled assessments of Head Start and the Chicago Child-Parent Centers programs suggest similar conclusions, although the data from Head Start represent only short-term effects.

\section{Early Intervention Programs for Disadvantaged Children}

Two different intervention programs, the Perry Preschool Program and the Abecedarian Program, have used randomized child assignment and long-term follow-up to study the effects of early interventions on social behaviors of severely disadvantaged children $(19,76)$. The Perry Program was an intensive preschool program that was administered to 64 disadvantaged, black children in Ypsilanti, Michigan between 1962 and 1967 (see Supplementary Material for details). The treatment consisted of a daily 2.5 hour classroom session on weekday mornings and a weekly 90 minute home visit by the teacher on weekday afternoons. The length of each preschool year was 30 weeks. The control and treatment groups have been followed through age 40. The Abecedarian Program involved111 disadvantaged children, born between 1972 and 1977, whose families scored high on a risk index (see Supplementary Material for details). The mean age at entry was 4.4 months. The program was a year-round, fullday intervention that continued through age 8 . The children were followed up until age 21 , and the project is ongoing.

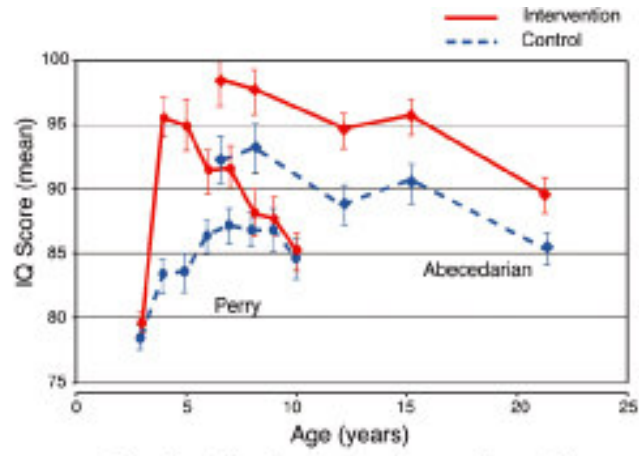

Figure 1. Mean IQ scores as a function of age for intervention and control groups in the Perry Preschool and Abecedarian Programs.

Notes: Perry: circles, Abecedarian: diamonds, red symbols: intervention group; blue symbols: matched control group. Bars indicate standard errors. Data from High/Scope and from the Carolina Abecedarian Project and the Carolina Approach to Responsive Education (CARE), 1972-1992.

In both the Perry and Abecedarian Programs there was a consistent pattern of successful outcomes for treatment group members compared with control group members. For the Perry Program, an initial increase in IQ (Fig. 1, red 
circles) disappeared gradually over 4 years following the intervention, as has been observed in other studies. However, in the more intense Abecedarian Program, which intervened earlier (starting at age 4 months) and lasted longer (until age 8), the gain in IQ (Fig. 1, red diamonds) persisted into adulthood (21 years old). This early and persistent increase in IQ is important because IQ is a strong predictor of socioeconomic success.
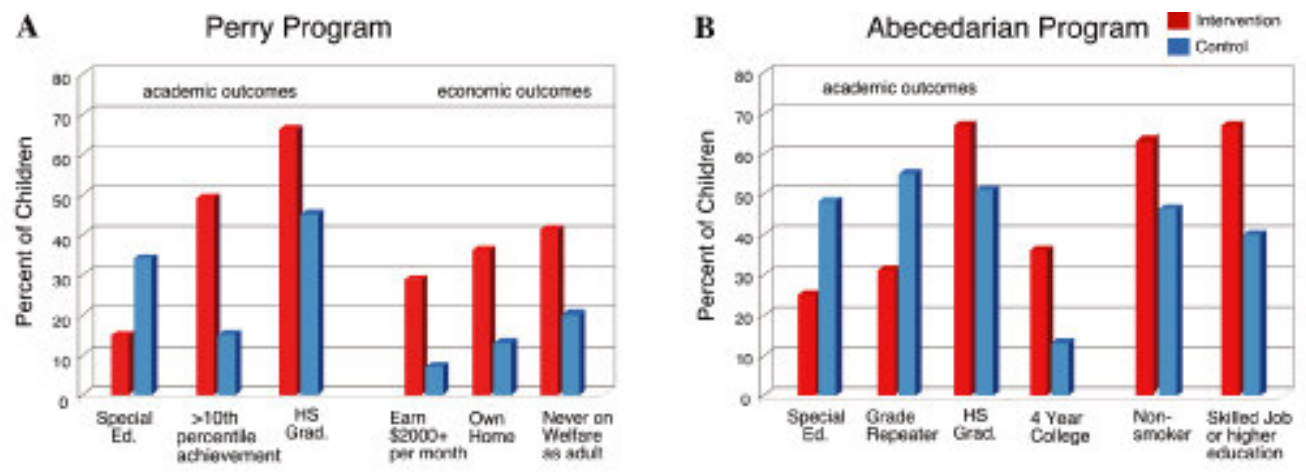

Figure 2. Academic, economic and social outcomes for the Perry Preschool and Abecedarian Programs.

Notes: A, Data from the Perry Program collected when the individuals were 27 years old (High/Scope). $>10$ th percentile achievement indicates children who scored above the lowest $10 \%$ on the California Achievement Test (1970) at age 14; HS Grad indicates number of children who graduated High School on time.

B, Data from the Abecedarian Program collected when the individuals were 21 years old (Carolina Abecedarian Project and the Carolina Approach to Responsive Education (CARE), 1972-1992). Red bers: intervention group; blue bars: control group.

Positive effects of these interventions were also documented for a wide range of social behaviors (Fig. 2). At the oldest ages tested (Perry: $40 \mathrm{yrs}$; Abecedarian: $21 \mathrm{yrs}$ ), individuals scored higher on achievement tests, reached higher levels of education, required less special education, earned higher wages, were more likely to own a home, and were less likely to go on welfare or be incarcerated than individuals from the control groups. Many studies have shown that these aspects of behavior translate directly or indirectly into high economic return. An estimated rate of return (the return per dollar of cost) to the Perry Program is in excess of 17\% (19). This high rate of return is much higher than standard returns on stock market equity and suggests that society at large can benefit substantially from these kinds of interventionnss.

Several observations about the evidence from these intervention studies are relevant to this paper (Fig. 3). First, skills beget skills. That is, all capabilities are built on a foundation of capacities that are developed earlier. This principle stems from two characteristics that are intrinsic to the nature of learning: (1) early learning confers value on acquired skills, which leads to self-reinforcing motivation to learn more; and (2) early mastery of a range of cognitive, social, and emotional competencies makes learning at later ages more efficient and therefore easier and more likely to continue.

Second, early intervention lowers the cost of later investment. For example, young children at risk for school failure who participate in early childhood programs are less likely to repeat grades or to require special education services (Fig. 2), thereby resulting in lower costs to the education system over time.

A more refined analysis of the intervention literature reveals significant increases in achievement across a broad range of outcomes (e.g., academic achievement tests, years of 
schooling completed, adult wages, and home ownership) among disadvantaged individuals as a result of exposure to an enriched preschool environment (Fig. 2). In most studies, these results are independent of IQ effects and are hypothesized to be related to differences in motivation, perseverance, temperament, and other dimensions of social competence as a result of the influence of enriched early experiences $(10,15-18)$. Some investigators have speculated that the positive effects of the early intervention programs are due to improvements in the social skills and emotional well-being of the children and that these effects, in turn, underlie the positive outcomes in school performance and wages earned later in adult life (19).

In contrast to the documentation of significant long-term effects from model preschool interventions, later remediation efforts have been shown to be considerably less effective (Fig. 3). School-age remedial programs for children and youth with cognitive limitations, for example, generally have had a poor record of success. Similarly, public job training programs, adult literacy services, prisoner rehabilitation programs, and education programs for disadvantaged adults have yielded low economic returns, with the returns for males often being negative (19). Moreover, for several studies in which later intervention showed benefits, the performance of these children was still behind the performances of children who experienced earlier interventions in the preschool years (19).

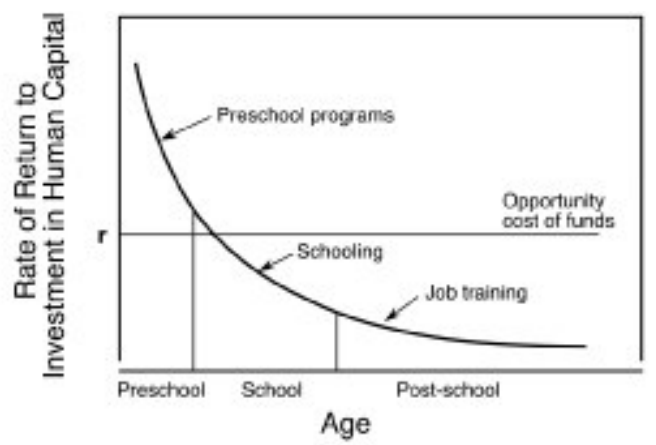

Figure 3. Rates of return to investment in human capital as function of age when the investment was initiated. Notes: The data were derived from a life cycle model of dynamic human capital accumulation with multiple periods and eredit constraints. Investments were initially set to be equal across all ages. " $\mathrm{r}$ " represents the cost of the funds. From Cunha, Heckman, Lochner and Masterov (19).

Although investments in older individuals realize relatively less return overall, such investments are still clearly beneficial. Indeed, the advantages gained from effective early interventions are sustained best when they are followed by continued high quality learning experiences (19). The technology of skill formation shows that the returns on school investment are higher for persons with higher ability, where ability is formed in the early years. Stated 
simply, early investments must be followed by later investments if maximum value is to be realized.

The studies cited above support the conclusion that early childhood experience has a powerful influence on the development of the cognitive, social, and emotional capacities that are prerequisites for strong economic productivity in adulthood. It is important to note, however, that the most convincing data for this assertion come from high quality intervention programs, which are not representative of the effectiveness of a wide range of services typically available to children from disadvantaged environments.

Ethical, practical, and cost considerations impose stringent limitations on how far research on humans can be pursued in rigorously controlled studies. Given these constraints, we turn to the research literature on other species to assess what has been learned about the fundamental principles of developmental neurobiology that might explain how early experience shapes social, emotional and cognitive capacities in a way that has a lasting impact into the adult years.

\section{Early Experience Shapes Temperament and Social Development}

Many of the emotional and social behaviors that are exhibited by humans are also observed in other species. Experiments with monkeys and rats, for example, have demonstrated that certain fundamental emotional and social behaviors are shaped dramatically by early experience (20-25). One of the most salient examples is the powerful influence of early interactions between an infant and its mother in shaping the temperament and social behavior of the developing animal. Much of this work has focused on the effects of early disruption of close affiliative bonds $(8,26-28)$.

In monkeys, considerable experimental work has demonstrated the extent to which the disruption of an early affiliative bond has long-term effects on the nature of an animal's interactions with other monkeys, leading to a decrease in affiliative behaviors and an increase in aggressive interactions later in life $(26,28,29)$. Although much of the evidence for these effects came originally from studies of monkeys reared in abnormal environments, such as in isolation or only with other young animals $(21,28-30)$, recent investigations have shown significant effects even when infants were reared in more normal, complex, social environments (Box 2). 


\section{Consequences of Early Affiliative Bond Disruption in Monkeys}

Numerous studies have documented the effects of removing the mother on the development of social and emotional behaviors in infant monkeys $(23,26)$. In a recent study, long-lasting behavioral effects were observed even when the infant monkeys remained in an otherwise complex social environment, i.e., the infants remained in a rich home environment, but their mothers were removed $(26,77)$.

Infants deprived of their mothers at one week of age developed normally in many respects. However, compared with infants reared with their mothers, they exhibited a striking decrease in social interactions with other monkeys and a sharp increase in self-comforting behaviors, such as thumb-sucking (Fig. 4, red open circles). In addition, they rarely sought social comfort when placed in anxiety-provoking situations, such as a novel playroom, tending instead to vocalize loudly and to engage in self-comforting behaviors. As they matured, they continued to exhibit fewer social interactions, such as touching and sitting in proximity to other monkeys. When placed in new social groups, they displayed other atypical social behaviors. For example, they exhibited a strong propensity to try social interactions with unfamiliar monkeys, including unusual levels of both affiliative and aggressive behaviors.

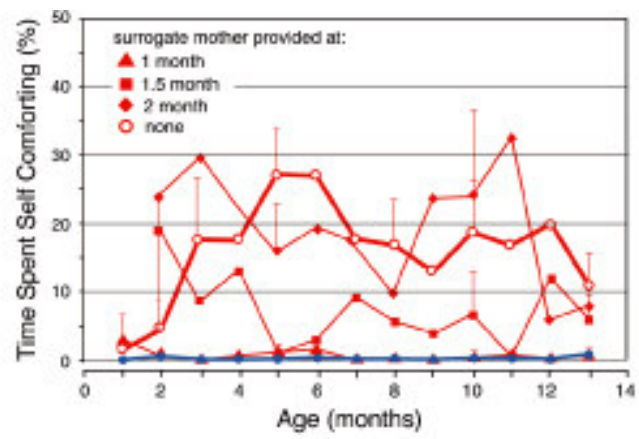

Figure 4. Sensitive period for remediation of aberrations in macaque social behavion caused by early life affiliative bond disruption.

Notes: Young monkeys whose mothers were present in the social group for the first 6 months of life (filled blue circles; $n=6$ ) spent very little time engaged in self-comforting behaviors (thumb-sucking, rocking) during the first year of life. In contrast, young monkeys who experienced removal of their mother from their social group at I week of age (open red circles, $n=6$ ) spent significantly more time displaying self-comforting behaviors throughout the first year of life (ANOVA, p<0.05). Introduction of a surrogate. nurturing mother at 1 month of age (red triangles, $n=3$ ) was effective in preventing the development of self-comforting behaviors. In contrast, introduction of a surrogate mother at 1.5 months of age was less effective in ameliorating self-comforting behaviors (filled squares, $\mathrm{n}=3$ ), and introduction of a surrogate mother at 2-2.5 months of age (filled diamonds: $\mathrm{n}=3$ ) was ineffective in ameliorating self-comforting behaviors. Bars indicate standard errors.

The nature and severity of the effects of removing the mother changed with the age of the infants at the time of separation. Once the infants had reached 6 months old, removal of the mother from the group had no apparent impact on the infant (Fig. 4, blue filled circles). In contrast, infants who had their mothers removed at one month of age exhibited acute withdrawal and depression, followed by increased seeking of social comfort from other monkeys and a variety of atypical social behaviors, many of which persisted into adulthood. Attempts to remediate the social and emotional consequences of early affiliative bond disruption generally had limited impact. Placing a nurturing surrogate mother into a social group with an infant deprived of its mother at one week of age was capable of normalizing many aspects of the infant's behavior (increasing time spent in social contact and decreasing the display of self-comforting behaviors) but only when the surrogate mother was introduced within the first month of the infant's life (Fig. 4, red triangles). Progressively later placement of the surrogate mother with the infant was progressively less effective in remediating the adverse behavioral consequences of early affiliative bond disruption (Fig. 4, red squares and diamonds).

These results demonstrate that, for monkeys, there is sensitive period when an early environment that lacks a close, nurturing relationship with a primary caregiver (mother or surrogate mother) results in adult monkeys who respond aberrantly to social signals and do not integrate well into social groups. The deleterious consequences of this impoverished early experience on these social and emotional behaviors become extremely difficult and, therefore, more costly to remediate at a later age. 
Studies in rodents also demonstrate that differences in affiliative behavior experienced early in life can have long-term effects on social behaviors and anxiety in adulthood (Box 3). These findings --- that both differences in, and disruptions of, close affiliative bonds early in life can have life-long effects on the development of social behaviors --- raise important concerns about the extent to which analogous early life experiences influence human development.

Extensive animal research also demonstrates the existence of sensitive periods, usually early in life, when the systems underlying the development of social skills are particularly plastic, followed by a period during which this plasticity decreases with age (Boxes 3 and 4)(3, $20,30,31)$. Together these findings argue strongly for early intervention programs to counteract adverse environmental circumstances that jeopardize the long-term development of social skills, which, in turn, are likely to affect an individual's long-term economic productivity. In a parallel fashion, developmental research in humans indicates that there may be sensitive periods in early childhood when greater responsiveness to therapeutic interventions might enhance life-long outcomes and decrease the probability of later mental health problems, such as anxiety or depression (32-36).

\footnotetext{
A Sensitive Period for Shaping the Temperament of Rodents

Certain aspects of the temperament of individual rats can be altered profoundly by early social experience (20, 24 , 67). For example, rat pups that are cared for during the first week after birth by a mother who grooms them extensively (high-grooming) and nurses them in a way that facilitates their access to milk (arched-back nursing) become more adventurous, less fearful, less anxious, and less reactive to stress than rat pups raised by a mother who does not act in this manner. These emotional traits, shaped by experience during this sensitive period, have positive effects on the development of the individual's social and cognitive behaviors that persist in adulthood.

Cross-fostering experiments show that the transmission of these traits is dominated by early experience, not by genetics $(67,78,79)$. Rats born to low-grooming mothers (non-attentive, little grooming, no arched-back nursing), but raised by high-grooming mothers, become themselves calm, adventurous adults and high-grooming parents. Conversely, rats born to high-grooming mothers, but reared by low-grooming mothers, become anxious adults and low-grooming parents. Thus, the transmission of these emotional and social traits is non-genetic, although without the intervention the traits would have seemed entirely genetically based. Experiments such as these demonstrate that although genetics constrains the ranges of social and emotional characteristics that an individual rat can express, early experience can modify these characteristics over remarkably large extents. The genetic and molecular mechanisms that underlie this particular influence of early social experience on temperament $(58,63)$ are described in Supplementary Material.
}

\section{Early Experience Shapes Perceptual and Cognitive Abilities}

The effects of early experience on perceptual and cognitive skills have been studied extensively by neuroscientists, and the same principles discussed above for social and emotional development hold true. Complex cognitive capacities, which mature and change throughout our 
lifetimes, depend on the analytic, synthetic, and recognition capabilities of specific neural circuits (37). The properties of many of these brain circuits have been shown to be particularly sensitive to the shaping influences of experience during early life (12, 31, 38-40).

Language acquisition in humans is a well studied example of a complex cognitive ability that is shaped by early experience (Box 4). All children at birth are capable of learning any of the world's languages. As they experience a particular language they become expert in analyzing, interpreting and producing its distinctive sounds, and individuals who are exposed to multiple languages during the early years of life learn to speak each with equal facility $(41,42)$. Social factors play an important role in regulating this early learning process, as both the production and the perception of speech are learned substantially faster when a child learns from a human tutor rather than from taped or video speech (41). Learning a second language as an adult requires far greater effort than learning it as a child, and the result is never as complete (Fig. 5). Thus, language acquisition demonstrates both the hierarchical nature of learning, i.e., early skills influence the ability to master later skills (43), and the phenomenon of sensitive periods in development, i.e., times early in life when specific abilities can be mastered and shaped more readily than later (42). 


\section{Sensitive Periods in the Acquisition of Language}

Language is an excellent and familiar example of a cognitive skill that is acquired readily in early life, but with great effort and never as thoroughly as an adult $(42,80)$. The dependence of language learning on age holds for first languages and second languages (Fig. 5), and for spoken languages as well as sign languages. For most people, a thorough command of language is attained when learning occurs before about 7 years of age. Statistically, language proficiency decreases progressively as language learning is delayed beyond 7 years, and reaches adult levels by the end of adolescence. People who have never experienced language throughout their childhood are apparently incapable of acquiring a facility with language at a later age, despite intense training. Not all aspects of language learning are subject to sensitive periods. For example, proficiency with phonetic comprehension and production, grammar and syntax is learned most effectively early in life, whereas semantics and vocabulary are learned with similar facility throughout life $(41,42,81)$.

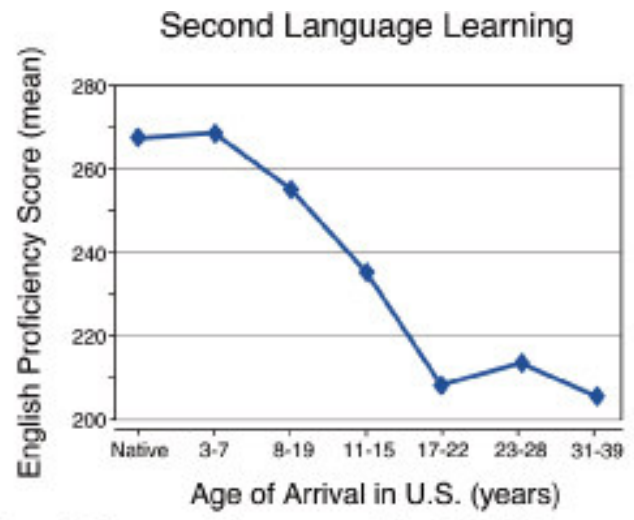

Figure 5. Sensitive period for second language acquisition. English language proficiency scores as a function of age of arrival in the United States for a group of Chinese and Korean adult immigrants $(n=46)$.

Notes: All subjects were students or faculty at the University of Illinois and had been in the U.S. for at least 10 years prior to testing. The test measured a variety of grammatic judgements. From Johnson and Newport (88).

For language, as for many cognitive skills, early learning begets later learning (43). In the first stage of language learning, young children learn to discriminate among acoustically similar sounds (phonemes) that convey different meaning (41). This learning is critical to the next stage of language acquisition, which is to learn to segment phonemes into words. Sound segmentation is critical, in turn, to attaching meaning to words and finally to deriving meaning from grammar and syntax. As predicted by this hierarchy of information processing, the ability of children to discriminate phonemes at 6 months of age predicts their ability to understand words and phrases at later ages, and an inability to discriminate phonemes leads to pervasive language disabilities later in life (82).

\section{Early Experience Shapes Brain Architecture}

In order to understand why early experience exerts such a powerful influence on skill development, we must understand how experience shapes the neural circuits that underlie all behavior. Although some capacity for plasticity persists in virtually all neural circuits throughout our lifetimes, many circuits are particularly susceptible to the influence of experience during sensitive periods as they are maturing(12) (Boxes 3 and 5).

A classic example of a neural circuit whose architecture is shaped by early experience is the circuit that conveys visual signals from the thalamus to the primary visual cortex in mammals 
$(44,45)$. When the quality of vision in one eye is substantially worse than that in the other, the axons conveying information from the disadvantaged eye disconnect from neurons in the visual cortex and withdraw most of their branches. Conversely, axons conveying information from the advantaged eye elaborate branches profusely and establish an abnormally high number of connections with cortical neurons $(46,47)$. This change in architecture is associated with a fundamental change in the function of the visual cortex, which becomes dominated by input from the advantaged eye. This effect of experience on brain architecture only occurs during a limited sensitive period in the development of this neural circuit, and once the circuit has matured the major effects are irreversible $(48,49)$.

The response of the brain to poor input from one eye is adaptive in that the nervous system alters its circuitry so that it differentially processes input from the superior eye. However, the inability of this circuit to recover normal architecture and function after the end of the sensitive period, even when input to the disadvantaged eye is restored, has no apparent adaptive advantage. This characteristic underscores the critical importance of normative early experience for the development of this neural circuit. As with skill development, an impoverished early environment results in a reduced capacity that is difficult or impossible to remediate at a later age.

In a different neural circuit, early experience has been shown to be capable of altering brain architecture in a way that greatly expands the capacity of the adult brain to process information adaptively (Box 5). In this case, early experience takes advantage of the increased capacity for neural plasticity in young animals to create new architectures that then persist into adulthood and support alternative ways of processing information (Fig. 6). As with the previous example, the capacity of the brain to make fundamental architectural changes guided by experience appears to be limited to a sensitive period in early life, in this case during the juvenile period (50). 


\begin{tabular}{|c|}
\hline A Sensitive Period for Changing Brain Architecture in Owls \\
\hline $\begin{array}{l}\text { The ability of early experience to instruct the functional properties and architecture of neural circuits has been } \\
\text { studied in the central auditory system of barn owls. Sound localization is a critical auditory function that allows } \\
\text { animals to find mates, avoid danger, and target prey based on the sounds they hear. For barn owls, as nocturnal } \\
\text { predators, sound localization is vital. To localize sounds, the central auditory system measures a variety of acoustic } \\
\text { cues, such as interaural time differences (ITDs) and interaural level differences (ILDs), and associates particular cue } \\
\text { values with the location in space that produces them. Behavioral studies on barn owls have shown that these cue- } \\
\text { location associations are shaped by experience most dramatically during a sensitive period that lasts until the } \\
\text { individual approaches adulthood (83). }\end{array}$ \\
\hline $\begin{array}{l}\text { Neural circuits responsible for establishing cue-location associations in the owl's central auditory system have been } \\
\text { identified (84). One pathway in the midbrain transforms a neural representation of ITD and ILD values into a } \\
\text { topographic map of space, in a structure called the external nucleus of the inferior colliculus (ICX). This auditory } \\
\text { space map is then sent to another structure, the optic tectum, where it merges with a visual map of space. }\end{array}$ \\
\hline $\begin{array}{l}\text { The representation of cues in the auditory space map is customized for the individual owl based on experience ( } 85 \text {, } \\
\text { 86). Manipulations of experience that alter auditory orienting behavior also alter the functional properties of neurons } \\
\text { in this circuit. The magnitudes of the changes that are induced by experience depend greatly on the age of the animal } \\
\text { (Fig. 6A). Large changes in neuronal response properties occur readily in juvenile owls and are accompanied by } \\
\text { anatomical changes in the pattern of projections of axons into the space map (50). The change in circuit architecture } \\
\text { that results from learning is due to the elaboration of axons and synapses in atypical portions of the ICX, as } \\
\text { instructed by experience (Fig. 6B, learned axons). Similar structural changes have been observed in the visual cortex } \\
\text { of kittens deprived of vision in one eye during a sensitive period (46). Once this additional circuitry is acquired and } \\
\text { stabilized as a consequence of learning, it becomes highly resistant to elimination and can persist into adulthood } \\
\text { (87). Owls that have learned an alternative map of auditory cues as juveniles can re-express that alternative map as } \\
\text { adults should it become adaptive once again (Fig. 4C), much like adult humans can readily re-learn a language that } \\
\text { they have learned as children. Thus, for this circuit, early learning establishes a brain architecture in juveniles that } \\
\text { enables increased functional plasticity in adulthood. }\end{array}$ \\
\hline
\end{tabular}



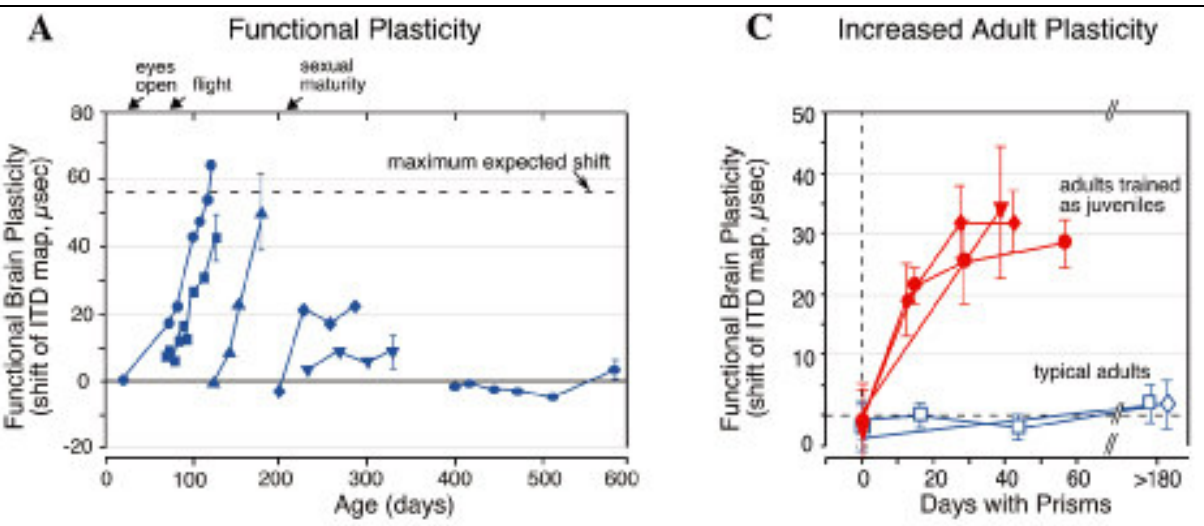

B Structural Plasticity

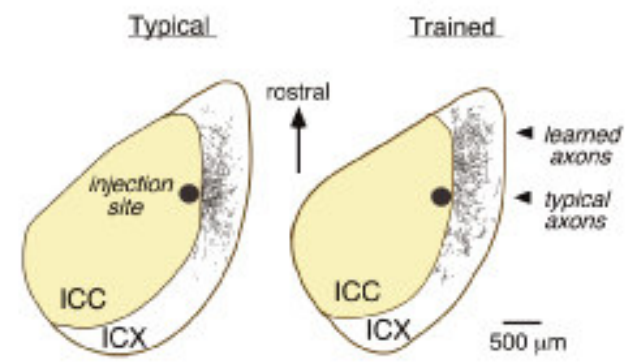

Figure 6. Functional and structural brain plasticity in the central auditory system of the barn owl.

Notes: A. Sensitive period for the visual calibration of the auditory system's map of interaural time difference (ITD) in the midbrain. The data indicate mean adaptive shifts in the turing of neurons in the optic tectum to ITD in 6 owls (different symbols) that resulted from experience with chronie displacement of the visual field with prismutie spectacles, beginning at different ages.

From Brainard and Knudsen (89).

B. Adaptive elaboration of axons and synapses in the brains of juvenile owls in response to experience with prism spectacles. Axon and synapse labeling in the extemal nucleus (ICX) following a tracer injection into the central nucleus (ICC) in a normal adult (typical) and in an owl that had acquired a learned ITD map as a juvenile (trained)

From DeBello, Feldman and Krudsen (50).

C. Early training leaves a memory trace that increases the capacity for functional plasticity in the adult brain. The data compare shifts in the ITD map in 2 typically reared adults (blue open symbols) with shifts in the ITD maps in 3 adults that had leamed the alternative ITD map previously as juveniles (red filled symbols). Recent experiments indicate that the increased functional plasticity in previously trained adults is due to the persistence of altered architecture (see B) acquired during juvenile learning (87)

From Knudsen (90)

In the hierarchies of neural circuits that support complex behavior, sensitive periods for circuits at lower levels in the hierarchy, which perform more fundamental computations, tend to close before those for circuits at higher levels $(38,51,52)$. For example, the sensitive period for circuits responsible for combining visual inputs from the two eyes ends long before the sensitive period for circuits responsible for recognizing biologically important objects $(38,53)$. This sequencing of sensitive periods is logical, because higher levels in a hierarchy depend on precise and reliable information from lower levels in order to accomplish their functions (i.e., early learning begets later learning, and skills beget skills). Thus, experience-dependent shaping of high-level circuits depends on the quality of the information provided by lower level circuits, and the shaping of high-level circuits cannot be completed until the computations carried out by 
lower-level circuits are stable and reliable. The sensitive periods for most lower-level circuits end relatively early in life (12). In contrast, sensitive periods for some high-level circuits remain open until the individual approaches adulthood (e.g., Boxes 4 and 5).

\section{Early Experience Shapes Gene Expression and Neurochemistry}

The activation of neural circuits by experience also can cause dramatic changes in the genes that are expressed ("turned on") in specific circuits (54-56). The protein products of these genes can have far reaching effects on the chemistry of neurons and therefore on their excitability and architecture. For example, induced gene products can regulate the formation or elimination of synaptic connections or the responsiveness of neurons to neural activity or to specific hormones, neuromodulators, or neurotransmitters (57-62). These changes can have an enormous impact on the properties of a neural circuit and on the behaviors that it mediates. Most importantly, some genes are turned on or off, or can have their expression levels adjusted by experience, only during a limited sensitive period in a circuit's maturation $(27,54,55,63-66)$.

A salient example of the effects of early experience on brain biochemistry and gene expression is the influence of early mothering of young rats on the release of "stress hormones" (glucocorticoids), and the subsequent life-long change in the expression of genes for glucocorticoid receptors in key regions of the brain (Box 3). In this example, early social interactions modify gene expression in a way that changes a critical set-point in a circuit that influences the animal's temperament throughout life(20,67). Beyond changing homeostatic setpoints in maturing neural circuits, experience-induced alterations in gene expression can lead to changes in patterns of connectivity, excitability, and biochemistry that alter how a circuit processes information and how it responds to circulating hormones, neuromodulators, and neurotransmitters well into adulthood $(45,60,67)$.

\section{Why Experience During Circuit Maturation Is So Effective}

The strong shaping influence of experience on neural circuits during their maturation results primarily from two factors. First, the molecular and cellular mechanisms that mediate neural plasticity during a sensitive period are highly active, enabling circuits to undergo substantial changes in architecture, chemistry, and gene expression in response to experiential 
influences $(12,31,45,68,69)$. After a sensitive period has passed, one or more of these critical mechanisms no longer operate or operate less effectively.

A second factor is that it is far easier to form a pattern of connections in a neural circuit that does not already have an established configuration. When a circuit first develops, patterns and strengths of connections form according to genetically encoded mechanisms, but these patterns tend to be relatively imprecise and the strengths tend to be relatively weak. Impulse activity that results from experience sharpens and strengthens these innate patterns of connections so that the circuit processes information in a certain way $(12,70,71)$. This shaping and strengthening process engages cellular and circuit level mechanisms that stabilize the instructed pattern of connectivity (such as synapse consolidation and lateral inhibition). Concurrently, these induced changes antagonize the formation of alternative patterns of connectivity, making it more difficult for subsequent experience to change the initial configuration $(12,72,73)$. Thus, the earliest experience is particularly influential because it has the unique advantage of instructing a pattern of connectivity in a circuit without interference from an already established pattern.

Both of these factors, the unique availability of highly effective plasticity mechanisms and the relative ease of forming the first strong pattern of connections, contribute to the powerful influence of early experience on the development of neural circuits. The first factor, however, is the most critical. Thus, as long as the appropriate mechanisms required for mediating change continue to operate effectively, experience that comes later in a sensitive period will overcome or add to the effects of earlier experience. However, later experience requires relatively more intensity and tends to be less efficacious (12).

\section{Conclusions and Implications}

Decades of research in developmental psychology have documented the highly interactive process through which children develop the cognitive, social, and emotional capacities that are foundational for school achievement and for adult economic productivity (3). In addition, extensive evidence from early intervention studies with disadvantaged children indicates that experience during early childhood can have a significant and lasting impact on a range of important adult outcomes $(13,14,33)$ : positive early experiences enable individuals to become more fit cognitively and emotionally. These findings are complemented by an extensive 
literature on human capital formation which indicates that later remediation of disadvantaged environments is much less effective than the provision of growth-promoting experiences early in life (19).

Supporting evidence for these conclusions comes from numerous studies of animal behavior, demonstrating that the early environments in which animals are reared exert powerful influences (both positive and negative) on their temperament, social behavior and cognitive skills, and that experiences later in life are substantially less effective in shaping many behaviors. It is important to note that the relevance of animal research to human circumstances rests not on the direct applicability of specific results to humans, but on the elucidation of underlying developmental and neurobiological principles. For example, the empirical findings of the positive effects of living in complex cages on learning capacity and brain architecture in young rats $(74,75)$ should not be equated with the relative impacts of a more or less stimulating home environment on the development of young humans. Rather, the value of such research lies in its demonstration of basic principles of neurobiology that apply across species --- the extent to which brain architecture is influenced by both experience and genetics, the hierarchical nature of brain and behavioral development, and the concepts of sensitive periods and decreasing neuroplasticity over time.

Our understanding of the mechanisms that underlie the far-reaching effects of early experience on the development of the brain and behavior is advancing at an accelerating pace. The development of the brain is driven by two interacting forces: genetics and experience. In recent years, neuroscientists have made considerable progress in elucidating how different experiences affect the architecture, biochemistry, and gene expression exhibited by neural circuits that mediate cognitive, emotional, and social behaviors. These shaping influences are particularly powerful during sensitive periods of circuit maturation, when specific circuit functions can be altered in fundamental ways that customize their information processing capabilities according to the demands of the experience. Across species, experience is essential to the unfolding of brain development, the more adaptable the species, the more experience plays a role. Later in life, equivalent experiences induce far more subtle changes.

The implications of this rapidly evolving science for human capital formation are striking. The workplace of the $21^{\text {st }}$ century will favor individuals with intellectual flexibility, strong problem-solving skills, emotional resilience, and the capacity to work well with others in 
a continuously changing and highly competitive economic environment. In this context, the personal and societal burdens of diminished capacity will be formidable, and the need to maximize human potential will be greater than ever before.

The evidence presented in this paper indicates that the most effectual and cost-effective strategy for strengthening the future American workforce is to invest greater human and financial resources in the social and cognitive environments of children who are disadvantaged, beginning in the earliest years. The greatest return derives from investing in disadvantaged children because their home environments are impoverished. Therefore, for them, the difference between the stimulating intervention environment and the environment they would otherwise experience is extremely large. In contrast, for typical children, the difference between the intervention environment and the home environment is small or nothing. Among disadvantaged children, the greatest return derives from investing in the earliest years because early experiences exert particularly powerful influences at a time when foundational skills and behavioral patterns are being established and when underlying neural circuits are most plastic and optimally receptive to alteration at fundamental levels of architecture, chemistry and gene expression. As the brain matures, experience continues to shape the neurobiology and behavioral manifestations of cognitive, emotional, and social capacities that, in turn, facilitate the subsequent development of a wide range of adult capabilities, including those that affect performance in the workplace.

The cognitively stimulating experiences in early childhood that are most important for the promotion of healthy development are provided through attentive, nurturing, and stable relationships with invested adults. When development is jeopardized by impaired relationships or other sources of environmental disadvantage, the biological and financial costs increase with age. Thus, although adaptation generally remains possible well into adult life, the decreasing plasticity of the maturing brain indicates that early intervention to mitigate the effects of disadvantaged environments is more efficient (in both energy costs to the nervous system and program costs to society) than later remediation for individuals with limited skills and problematic behavior. Stated simply, skills beget skills, success breeds success, and the provision of positive experiences early in life is considerably less expensive and more effective than the cost and effectiveness of corrective intervention at a later age. The issue of what the optimal strategies might be for maximizing the productivity of the future U.S. workforce is beyond the scope of the current discussion. However, as we confront the human capital needs of the future, 
the findings of neuroscience, behavioral research, and economics all agree on the following conclusion --- prevention is more effective and less costly than remediation, and earlier is far better than later.

Acknowledgements: This paper was conceived and written under the auspices of the National Scientific Council on the Developing Child, with support from the John D. and Catherine T. MacArthur Foundation, the Susan A. Buffett Foundation, the Buffett Early Childhood Fund, and the Johnson \& Johnson Pediatric Institute. The authors acknowledge support by grants from the MacArthur Research Network on Early Experience and Brain Development, the National Institutes of Deafness and Other Communication Disorders to E.I.K., and the PEW Foundation through the Committee on Economic Development and from NICHD to J.J.H. We thank P. Knudsen for design of the figures. 


\section{$\underline{\text { References }}$}

1. Ellwood, D. (2001) The sputtering labor force of the 21st century: can social policy help? (Russell Sage Foundation, New York).

2. DeLong, J., B., Goldin, C. \& Katz, L. (2003) Sustaining U.S. economic growth (The Brookings Institution, Washington D.C.).

3. Shonkoff, J. \& Phillips, D. (2000) From Neurons to Neighborhoods: The Science of Early Childhood Development (National Academy Press, Washington D.C.).

4. Rutter, M. L., Kreppner, J. M. \& O'Connor, T. G. (2001) Br J Psychiatry 179, 97-103.

5. Tennant, C. (1988) Arch Gen Psychiatry 45, 1045-50.

6. Goodman, S. H. \& Gotlib, I. H. (1999) Psychol. Rev. 106, 458-490.

7. Cicchetti, D. \& Toth, S. L. (1995) J. Am. Acad. Child Adolesc. Psychiatry 34, 541-565.

8. Heim, C. \& Nemeroff, C. B. (2001) Biol. Psychiatry 49, 1023-1039.

9. Carneiro, P. \& Heckman, J. J. (2003) Inequality in America: What Role for Human Capital Policy? (MIT Press, Cambridge, MA).

10. Currie, J. \& Blau, D. (2005) Preschool, day care, and afterschool care: who's minding the kids? (North Holland, Amsterdam).

11. Katz, L. C. \& Shatz, C. J. (1996) Science 274, 1133-1138.

12. Knudsen, E. I. (2004) J Cogn Neurosci 16, 1412-25.

13. Campbell, F. \& Ramey, C. (1994) Child Development 65, 684-698.

14. Schweinhart, L. J., Montie, J., Xiang, Z., Barnett, W. S., Belfield, C. R. \& Nores, M. (2005) Lifetime Effects: The High/Scope Perry Preschool Study Through Age 40 (High/Scope Press, Ypsilanti).

15. Barnett, W. S. (1995) The Furture of Children 5, 25-50.

16. Yoshikawa, H. (1995) The Future of Children 5, 51-75.

17. Olds, D. L., Kitzman, H., Cole, R., Robinson, J., Sidora, K., Luckey, D. W., Henderson, C. R., Jr., Hanks, C., Bondy, J. \& Holmberg, J. (2004) Pediatrics 114, 1550-9.

18. Love, J. M., Kisker, E. E., Ross, C., Raikes, H., Constantine, J., Boller, K., Brooks-Gunn, J., Chazan-Cohen, R., Tarullo, L. B., Brady-Smith, C., Fuligni, A. S., Schochet, P. Z., Paulsell, D. \& Vogel, C. (2005) Dev Psychol 41, 885-901.

19. Cunha, F., Heckman, J., Lochner, L. \& Masterov, D. (2005) Interpreting the evidence on life cycle skill formation (North Holland, Amsterdam).

20. Meaney, M. J. (2001) Annu Rev Neurosci 24, 1161-92.

21. Suomi, S. J. (1981) Genetic, maternal, and environmental influences on social development in rhesus monkeys.

22. Liu, D., Diorio, J., Day, D. C., Francis, D. D. \& Meaney, M. J. (2000) Nat. Neurosci. 3, 799-806.

23. Coplan, J. D., Rosenblum, L. A. \& Gorman, J. M. (1995) Psychiatr. Clin. North Am. 18, 727-743.

24. Caldji, C., Tannenbaum, B., Sharma, S., Francis, D., Plotsky, P. M. \& Meaney, M. J. (1998) Proc Natl Acad Sci U S A 95, 5335-40.

25. Sanchez, M. M., Ladd, C. O. \& Plotsky, P. M. (2001) Dev Psychopathol 13, 419-49.

26. Nelson, C. A., Bloom, F. E., Cameron, J. L., Amaral, D., Dahl, R. E. \& Pine, D. (2002) Dev Psychopathol 14, 499-520. 
27. Meaney, M. J., Diorio, J., Francis, D., Widdowson, J., LaPlante, P., Caldji, C., Sharma, S., Seckl, J. R. \& Plotsky, P. M. (1996) Dev Neurosci 18, 49-72.

28. Suomi, S. J., Collins, M. L., Harlow, H. F. \& Ruppenthal, G. C. (1976) J Child Psychol Psychiatry 17, 101-12.

29. Kraemer, G., Ebert, M., Schmidt, D. \& McKinney, W. (1991) Child Development 62, 548-566.

30. Harlow, H. F. \& Marlow, M. K. (1962) Sci. American 207, 136-146.

31. Horn, G. (2004) Nat Rev Neurosci 5, 108-20.

32. Luby, J. (2000) in Handbook of Infant Mental Health, ed. Zeanah, C. (The Guilford Press, New York).

33. Shonkoff, J. \& Meisels, S. (2000) Handbook of Early Childhood Intervention (Cambridge University Press, New York).

34. Mifsud, C. \& Rapee, R. M. (2005) J Am Acad Child Adolesc Psychiatry 44, 996-1004.

35. Ramey, S. L. \& Ramey, C. T. (1999) Mental Retardation and Developmental Disabilities Research Reveiws 5, 1-10.

36. Belsky, J. (2006) Dev. Psychol. 42, 38-58.

37. Shaw, P., Greenstein, D., Lerch, J., Clasen, L., Lenroot, R., Gogtay, N., Evans, A., Rapoport, J. \& Giedd, J. (2006) Nature 440, 676-9.

38. Pascalis, O., Scott, L. S., Kelly, D. J., Shannon, R. W., Nicholson, E., Coleman, M. \& Nelson, C. A. (2005) Proc Natl Acad Sci U S A 102, 5297-300.

39. Brunson, K. L., Kramar, E., Lin, B., Chen, Y., Colgin, L. L., Yanagihara, T. K., Lynch, G. \& Baram, T. Z. (2005) J Neurosci 25, 9328-38.

40. Schorr, E. A., Fox, N. A., van Wassenhove, V. \& Knudsen, E. I. (2005) Proc Natl Acad Sci U S A 102, 18748-50.

41. Kuhl, P. K. (2004) Nat Rev Neurosci 5, 831-43.

42. Newport, E. L., Bavelier, D. \& Neville, H. J. (2001) in Language, brain and cognitive development: Essays in honor of Jacques Mehler, ed. Doupoux, E. (MIT Press, Cambridge, MA), pp. 481-502.

43. Morgan, J. L. \& Demuth, K. (1996) Signal to Syntax: Bootstrapping from Speech to Grammar in Early Acquisition (Lawrence Erlbaum Associates, New Jersey).

44. Hubel, D. H., Wiesel, T. \& LeVay, S. (1977) Phil Trans $R$ Soc Lond B 278, 377-409.

45. Hensch, T. K. (2005) Curr Top Dev Biol 69, 215-37.

46. Antonini, A. \& Stryker, M. P. (1996) J Comp Neurol 369, 64-82.

47. Antonini, A., Fagiolini, M. \& Stryker, M. P. (1999) J Neurosci 19, 4388-406.

48. Wiesel, T. N. \& Hubel, D. H. (1965) J. Neurophysiol. 28, 1060-1072.

49. Jampolsky, A. (1978) in Symposium on strabismus, Trans New Orleans Acad Ophthal, pp. Chapter 26, pp. 358-492.

50. DeBello, W. M., Feldman, D. E. \& Knudsen, E. I. (2001) J. Neurosci. 21, 3161-74.

51. Jones, K. R., Spear, P. D. \& Tong, L. (1984) J. Neurosci. 4, 2543-2552.

52. $\quad$ DeBello, W. M. \& Knudsen, E. I. (2004) J Neurosci 24, 6853-61.

53. Daw, N. W. (1997) Optometry and Vision Science 74, 690-694.

54. Tagawa, Y., Kanold, P. O., Majdan, M. \& Shatz, C. J. (2005) Nat Neurosci 8, 380-8.

55. Corriveau, R. A., Huh, G. S. \& Shatz, C. J. (1998) Neuron 21, 505-20.

56. Kaczmarek, L. \& Chaudhuri, A. (1997) Brain Res Brain Res Rev 23, 237-56.

57. Kelly, M. P. \& Deadwyler, S. A. (2003) J Neurosci 23, 6443-51. 
58. Weaver, I. C., Champagne, F. A., Brown, S. E., Dymov, S., Sharma, S., Meaney, M. J. \& Szyf, M. (2005) J Neurosci 25, 11045-54.

59. Wang, H. G., Lu, F. M., Jin, I., Udo, H., Kandel, E. R., de Vente, J., Walter, U., Lohmann, S. M., Hawkins, R. D. \& Antonova, I. (2005) Neuron 45, 389-403.

60. Kandel, E. R. (2001) Science 294, 1030-8.

61. Cabelli, R. J., Shelton, D. L., Segal, R. A. \& Shatz, C. J. (1997) Neuron 19, 63-76.

62. Huh, G. S., Boulanger, L. M., Du, H., Riquelme, P. A., Brotz, T. M. \& Shatz, C. J. (2000) Science 290, 2155-9.

63. Weaver, I. C., Diorio, J., Seckl, J. R., Szyf, M. \& Meaney, M. J. (2004) Ann N Y Acad Sci 1024, 182-212.

64. Philpot, B. D., Sekhar, A. K., Shouval, H. Z. \& Bear, M. F. (2001) Neuron 29, 157-69.

65. Huang, Z. J., Kirkwood, A., Pizzorusso, T., Porciatti, V., Morales, B., Bear, M. F., Maffei, L. \& Tonegawa, S. (1999) Cell 98, 739-55.

66. Corriveau, R. A., Shatz, C. J. \& Nedivi, E. (1999) J Neurosci 19, 7999-8008.

67. Weaver, I. C., Cervoni, N., Champagne, F. A., D'Alessio, A. C., Sharma, S., Seckl, J. R., Dymov, S., Szyf, M. \& Meaney, M. J. (2004) Nat Neurosci 7, 847-54.

68. Berardi, N., Pizzorusso, T. \& Maffei, L. (2000) Curr Opin Neurobiol 10, 138-45.

69. Daw, N. W. (1994) Invest Ophthal and Vis. Sci. 35, 4168-4179.

70. $\quad$ Engert, F., Tao, H. W., Zhang, L. I. \& Poo, M. M. (2002) Nature 419, 470-5.

71. Lu, W. \& Constantine-Paton, M. (2004) Neuron 43, 237-49.

72. Hensch, T. K. (2005) Nat Rev Neurosci 6, 877-88.

73. Zheng, W. \& Knudsen, E. I. (2001) J. Neurosci. 21, 4356-4365.

74. Grossman, A. W., Churchill, J. D., McKinney, B. C., Kodish, I. M., Otte, S. L. \& Greenough, W. T. (2003) J Child Psychol Psychiatry 44, 33-63.

75. Cancedda, L., Putignano, E., Sale, A., Viegi, A., Berardi, N. \& Maffei, L. (2004) J Neurosci 24, 4840-8.

76. Barnett, S. \& Masse, L. N. (2002) (National Institute for Early Education Research (NIEER), New Brunswick, New Jersey.

77. McCormick, K., Kerr, D., Rockcastle, N., Bytheway, J., Colosimo, D., Singer, L. \& Cameron, J. L. (2004) Soc. Neurosci. Abstr. 426, 20.

78. Liu, D., Diorio, J., Tannenbaum, B., Caldji, C., Francis, D., Freedman, A., Sharma, S., Pearson, D., Plotsky, P. M. \& Meaney, M. J. (1997) Science 277, 1659-62.

79. Francis, D., Diorio, J., Liu, D. \& Meaney, M. J. (1999) Science 286, 1155-8.

80. Doupe, A. J. \& Kuhl, P. K. (1999) Annu. Rev. Neurosci. 22, 567-631.

81. Neville, H. J., Mills, D. L. \& Lawson, D. S. (1992) Cereb Cortex 2, 244-58.

82. Tsao, F. M., Liu, H. M. \& Kuhl, P. K. (2004) Child Dev 75, 1067-84.

83. Knudsen, E. I. (1999) J. Comp. Physiol. 185, 305-321.

84. Knudsen, E. I. (2002) Nature 417, 322-8.

85. Brainard, M. S. \& Knudsen, E. I. (1993) J. Neurosci. 13, 4589-4608.

86. Gold, J. I. \& Knudsen, E. I. (2000) J. Neurosci. 20, 862-77.

87. Linkenhoker, B. A., von der Ohe, C. G. \& Knudsen, E. I. (2005) Nat Neurosci 8, 93-8.

88. Johnson, J. S. \& Newport, E. L. (1989) Cognit Psychol 21, 60-99.

89. Brainard, M. S. \& Knudsen, E. I. (1998) J. Neurosci. 18, 3929-3942.

90. Knudsen, E. I. (1998) Science 279, 1531-1533. 


\section{$\underline{\text { Supplemental Material }}$}

\section{Early Intervention Programs for Disadvantaged Children}

The Perry Preschool Program and the Abecedarian Program used randomized child assignment and long-term follow-up to study the effects of early interventions on social behaviors of severely disadvantaged children (1-3). The Perry Program was an intensive preschool program that was administered to 64 disadvantaged, black children in Ypsilanti, Michigan between 1962 and 1967. Experimental and control group assignments were performed randomly in the following way. Candidate children were selected from students attending the Perry School, from neighborhood group referrals, and from door to door canvassing. Poor children who scored between 75 and 85 on the Stanford-Binet IQ test were randomly divided into two undesignated groups. The children were then transferred across groups to equalize socioeconomic status, cognitive abilities (as measured by IQ), and gender composition. Finally, a coin toss determined which group would receive the treatment and which would not. Initially, the treatment and control groups each comprised 64 children, but the final treatment and control groups comprised 58 and 65 children, respectively.

Children entered the Perry Program in five cohorts, starting with cohort zero (four-yearolds) and cohort one (three-year-olds) in 1962. Then, cohorts two, three and four (three-yearolds) entered in each subsequent year through 1965. The average age at entry was 42.3 months. With the exception of cohort zero, treatment children spent two years attending the program. In the final year of the program, 11 three-year-olds, who were not included in the data, attended the program with the 12 four-year-olds, who were included in the data. About half of the children were living with two parents. The average mother was 29 years old and had completed 9.4 years of school.

The treatment consisted of a daily 2.5 hour classroom session on weekday mornings and a weekly 90 minute home visit by the teacher on weekday afternoons to involve the mother in the educational process. The length of each preschool year was 30 weeks, beginning in midOctober and ending in May. Ten female teachers participated, resulting in an average child:teacher ratio of 6:1 for the duration of the program. All teachers were certified to teach in elementary, early childhood or special education. If it were administered today, the Perry Preschool Program would cost approximately $\$ 9,785$ per participant per year in 2004 dollars (1). The control and treatment groups have been followed through age 40 .

The Abecedarian Program recruited 111 children, born between 1972 and 1977, whose families scored high on a risk index, which consisted of weighted measures of maternal and paternal education levels, family income, absence of the father from the home, poor social or family support for the mother, indications that older siblings had academic problems, the use of welfare, unskilled employment, low parent IQ, and family members who sought counseling or support from various community agencies. Parental income and education were considered most important in calculating the index. The Program enrolled children beginning a few months after birth. Enrollment was based on the characteristics of the families more than on the characteristics of the children, as in the Perry Program. Virtually all of the children were black, and their parents had low levels of education, income, and cognitive ability and high levels of pathological behavior. The children were screened for mental retardation. Most of the children (76\%) lived in single parent or multigenerational households. The average mother was just under 20 years old and had 10 years of schooling and an IQ of 85. 
The Abecedarian Program involved 4 cohorts of approximately 28 children each. By the time they were 6 weeks old, the children were assigned randomly to either a preschool intervention or a control group. The mean age at entry was 4.4 months. At age 5 (just as they were about to enter kindergarten), all of the children were reassigned to either a school age intervention group through age 8 or to a control group. This yielded 4 groups: children who experienced no intervention, those who experienced an intervention when they were young, those who experienced an intervention when they were older, and those who experienced an intervention throughout their whole childhood. The children were followed up until age 21.

The Abecedarian Program was more intensive than the Perry Program. The Abecedarian Program was a year-round, full-day intervention. The initial infant:teacher ratio was 3:1, though it increased to a child:teacher ratio of 6:1 as the children progressed through the program. During the first 3 primary school years, an additional home-school teacher met with the parents and helped them in providing supplemental educational activities at home. The teacher provided an individually-tailored curriculum for each child. The target set for the parents was at least 15 minutes per day of supplementary activities. This home-school teacher also served as a liaison between the ordinary teachers and the family, and she interacted with the parents and the teachers every two weeks. She also helped the parents deal with other issues to improve their ability to care for the child, such as finding employment, navigating the bureaucracy of social services agencies, and transporting children to appointments. Data were collected regularly up to age 21 , and the project is on going.

\section{A Sensitive Period for Shaping the Temperament of Rodents}

Extensive grooming during early life causes rats to express low resting levels of stress hormones, called glucocorticoids. Low levels of glucocorticoids give rise to feelings of calmness, whereas high levels give rise to feelings of anxiety and fear. Glucocorticoid hormones are released by the adrenal glands in response to environmental stressors. A structure in the brain called the hippocampus contains glucocorticoid receptors (GRs) and exerts negative feedback control on the amount of glucocorticoids that are released by the adrenal glands.

The mechanisms work in the following way $(4,5)$. A rat pup's experience with a highgooming mother increases the levels of the neuromodulator serotonin in the pup's hippocampus, leading, in turn, to an increase in the transcription (turning on) of the GR gene. The resulting high level of GRs in the hippocampus establishes strict control of glucocorticoid hormone release by the adrenal glands and, consequently, low basal levels of stress hormones and low reactivity of the individual to stressors. As a result, these rats are calm and not easily frightened. Rat pups that are raised by low-grooming mothers exhibit the opposite effects: decreased serotonin levels in the hippocampus, a consequent down-regulation (turning off) of the GR gene and GRs, leading to high basal levels of stress hormones and high reactivity to stressors. These pups are more anxious individuals and, as adults, become low-grooming mothers. Because the gene for GRs is altered naturally by this kind of experience only during the first week after birth (6), there is only this limited period in life when experience can change a rat's emotional temperament by this mechanism, and the consequences are long lasting. 
1. Cunha, F., Heckman, J., Lochner, L. \& Masterov, D. (2005) Interpreting the evidence on life cycle skill formation (North Holland, Amsterdam).

2. Barnett, S. \& Masse, L. N. (2002) National Institute for Early Education Research (NIEER), New Brunswick, New Jersey.

3. Schweinhart, L. J., Montie, J., Xiang, Z., Barnett, W. S., Belfield, C. R. \& Nores, M. (2005) Lifetime Effects: The High/Scope Perry Preschool Study Through Age 40 (High/Scope Press, Ypsilanti).

4. Meaney, M. J. (2001) Annu Rev Neurosci 24, 1161-92.

5. Weaver, I. C., Cervoni, N., Champagne, F. A., D'Alessio, A. C., Sharma, S., Seckl, J. R., Dymov, S., Szyf, M. \& Meaney, M. J. (2004) Nat Neurosci 7, 847-54.

6. Weaver, I. C., Champagne, F. A., Brown, S. E., Dymov, S., Sharma, S., Meaney, M. J. \& Szyf, M. (2005) J Neurosci 25, 11045-54. 